\title{
Night blindness and conjunctival xerosis caused by vitamin A deficiency in patients with cystic fibrosis
}

\author{
R J RAYNER, ${ }^{*}$ J C TYRRELL,${ }^{*}$ E J HILLER, ${ }^{*}$ C MARENAH, $\dagger$ M A NEUGEBAUER, $\ddagger$ \\ $S$ A VERNON, $\ddagger$ AND G BRIMLOW $\ddagger$
}

Departments of *Paediatrics, and †Clinical Chemistry, City Hospital, and $¥$ Department of Ophthalmology, University Hospital, Nottingham

SUMMARY Forty three patients with cystic fibrosis, aged 8-44 years (median 16 years), were examined for evidence of vitamin A deficiency. Eight patients had abnormal dark adaptation tests and three had conjunctival xerosis. Serum vitamin $\mathrm{A}$ and retinol binding protein concentrations were significantly lower in the affected patients who were also more likely to have abnormal liver function tests. Five patients were treated with 100 000-200 000 IU water miscible vitamin A orally and their daily vitamin supplements were increased to maintain normal concentrations. In four patients dark adaptation tests were repeated. Three were normal, but one patient required three further doses of water miscible vitamin A and a daily supplement of 12000 IU vitamin A before her dark adaptation threshold returned to normal. Adolescents with cystic fibrosis are liable to develop night blindness and conjunctival xerosis, particularly if they have liver disease or fail to take daily vitamin supplements.

When the pathological features of cystic fibrosis were first described by Andersen there was evidence of vitamin A deficiency in the conjunctivas or respiratory epithelia of 10 of the 44 patients reported. ${ }^{1}$ Subsequent studies have shown that despite taking vitamin supplements and pancreatic enzymes to control malabsorption, patients with cystic fibrosis tend to have low serum concentrations of vitamin A. ${ }^{2}{ }^{3}$ Vitamin $\mathrm{A}$ is stored in the liver and released bound to retinol binding protein. Normally, serum levels of vitamin $\mathrm{A}$ and retinol binding protein reflect the state of liver stores. Some patients with cystic fibrosis, however, have low levels of retinol binding protein and serum vitamin A despite raised concentrations of vitamin $A$ in the liver, which suggests that release of vitamin A from liver stores may be defective. ${ }^{45}$

Vitamin $A$ is essential for the synthesis of rhodopsin in the retina, and an early symptom of vitamin A deficiency is night blindness. It is also necessary for the maintenance of secretory epithelia. ${ }^{6}$ When vitamin A deficiency is of long standing, keratinising squamous metaplasia of the conjunctiva occurs leading to conjunctival xerosis, and eventually to xerophthalmia with corneal ulceration.

There have been few reports of clinical problems caused by vitamin A deficiency in patients with cystic fibrosis. ${ }^{7-9}$ Fulton et al investigated dark adaptation in 56 patients with cystic fibrosis and found that mean thresholds were higher in patients than in controls. Two of their patients had night blindness that responded to treatment with water miscible vitamin A. ${ }^{10}$ Only 15 patients, however, were able to produce a full dark adaptation curve.

This study was designed firstly to establish the incidence of clinically important vitamin A deficiency in a population of patients old enough to perform a full dark adaptation test, and secondly to determine the optimum treatment for affected patients.

\section{Patients and methods}

Fifty two patients attending the cystic fibrosis clinic in Nottingham who were old enough to perform a dark adaptation test were invited to take part in the study. All patients were taking two multivitamin tablets (5000 IU vitamin A and 100-200 mg vitamin E) daily and all except two were taking enteric coated pancreatic enzyme supplements. Four normal adolescents aged 14-16 years acted as controls.

Although it is customary to measure serum vitamin concentrations when patients had fasted, this was not possible because the outpatient clinic was held in the afternoon. Vitamin supplements had 
been taken before breakfast, at least six hours before blood was taken. Venous blood $(5 \mathrm{ml})$ was taken and kept in the dark and the serum was separated and stored at $-70^{\circ} \mathrm{C}$ until analysis. Vitamins $\mathrm{A}$ and $\mathrm{E}$ were measured by high performance liquid chromatography and retinol binding protein by an immunodiffusion kit (LC Partigen, Behring). The results of liver function tests carried out within three months of the dark adaptation test were recorded. These included estimations of serum alkaline phosphatase and $\gamma$ glutamyltransferase activity, and measurements of the concentrations of albumin and bilirubin.

All patients had their visual acuity measured and their eyes were examined with a slit lamp and ophthalmoscope. Thirty one patients performed dark adaptation tests by two methods: a modification of the Friedmann field analyser (measuring total retinal response) and a computer system (measuring point retinal responses to red and green spots of light). In both tests the retina was first bleached by exposure to a bright light. The subject then sat in the dark, and the intensity at which a stimulus was first detected was measured every few minutes. The minimum intensity at which a stimulus could be detected after 30 minutes was called the dark adaptation threshold. If rod vision is impaired, the dark adaptation threshold is raised. Because normal values for $\log$ (dark adaptation threshold) measured by the computer system rise slightly with age, the log (dark adaptation threshold) for each patient was expressed as the number of standard deviations from the expected mean for age. ${ }^{11}$

As the computer system was found to be a more sensitive test and was easier for the younger patients to perform, this alone was used for 12 further patients and for the follow up of the abnormal patients.

The first two affected patients to be treated were given standard oil based preparations of vitamin A intramuscularly or orally. In patients with malabsorption, water miscible preparations of the fat soluble vitamins are preferable. ${ }^{12}$ Subsequent affected patients were given a single oral dose of 100 000-2000000 IU water miscible vitamin A palmitate (Arovit, Hoffmann La Roche, supplied for named patients) as recommended by the World Health Organisation. ${ }^{13}$ The daily dose of vitamin A was then adjusted according to the serum concentration. Dark adaptation tests were repeated at intervals and further doses of water miscible vitamin $\mathrm{A}$ given until the serum vitamin $A$ concentration remained in the normal range and the dark adaptation threshold returned to normal.

Results were analysed by the Student's $t$ test, the Mann-Whitney U test, Spearman's rank correlation coefficient and the $\chi^{2}$ test where appropriate using Oxstat programs (Medstat).

\section{Results}

Thirty one of the 52 patients who were eligible for the study attended their first appointment. Twelve patients who failed to attend and who were subsequently found to have serum vitamin A concentrations below the normal range attended a second appointment. The median age of these 43 patients was 16 years (range 8-44) and the median Shwachman score was 60 (range 34-95). ${ }^{14}$ Nutritional and respiratory variables are shown in table 1 .

All patients had normal visual acuity and normal fundi. Eight patients had dark adaptation thresholds more than two standard deviations above the expected mean using the computer system. Two of

Table 1 Nutritional and respiratory variables in the 43 patients studied

\begin{tabular}{llc}
\hline & Median & Range \\
\hline Weight (\% expected) & 85 & $53-126$ \\
Height (\% expected) & 98 & $85-110$ \\
Weight for height (\% expected) & 90 & $70-120$ \\
Forced expiratory volume in 1 second & & \\
$\quad$ (\% expected) & 54 & $16-108$ \\
Forced vital capacity (\% expected) & 71 & $22-100$ \\
Chrispin-Norman score & 18 & $2-30$ \\
Shwachman score & 60 & $33-95$ \\
\hline
\end{tabular}

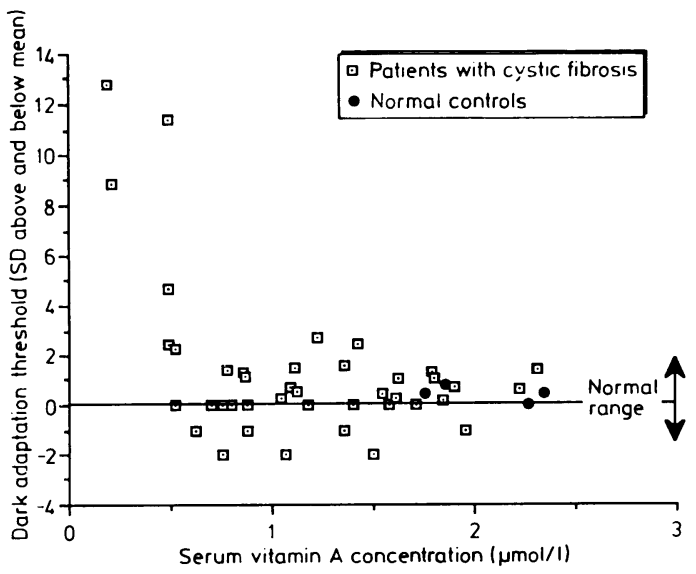

Fig 1 The association between the dark adaptation threshold (expressed as the number of standard deviations from the expected mean for age) and the serum vitamin $A$ concentrations in 43 patients with cystic fibrosis and four normal controls. 
the eight had normal dark adaptation tests using the Friedmann field analyser and had vitamin $\mathrm{A}$ and retinol binding protein concentrations within the normal ranges. The other six all had serum vitamin A concentrations below $0.7 \mu \mathrm{mol} / 1$ and low retinol binding protein concentrations, and four had abnormal Friedmann tests. Four of the six had experienced symptoms of night blindness but had not reported them.

Fig 1 shows the rapid rise in the dark adaptation threshold when the serum vitamin A concentration fell below $0.7 \mu \mathrm{mol} / 1$. The four normal controls all had dark adaptation thresholds within one standard deviation of the expected mean.

Two of the patients with abnormal dark adaptation, and one other patient, had conjunctival xerosis (as previously reported ${ }^{15}$ ), so that a total of nine patients had clinical evidence of vitamin A deficiency.

The median (range) serum vitamin A concentration for the 43 patients was reduced at $1.07 \mu \mathrm{mol} / \mathrm{l}$ $(0 \cdot 19-2 \cdot 3)$ compared with $2 \cdot 0 \mu \mathrm{mol} / 1(1 \cdot 76-2 \cdot 35)$ for the controls (adult normal range 1.08-7.0 $\mu \mathrm{mol} / \mathrm{l}$ ) $(p=0.0005)$. The median serum retinol binding protein concentration was $18.7 \mathrm{mg} / \mathrm{l}(1-46)$ (adult normal range $30-60 \mathrm{mg} / \mathrm{l}$ ) and retinol binding protein concentrations were significantly correlated with serum vitamin A concentrations ( $r s=0 \cdot 77$, $\mathrm{p}<0 \cdot 0001$ ). When the nine affected patients were compared with the other 34 patients, serum vitamin $A$ and retinol binding protein concentrations were significantly lower in the affected group (table 2).

The median serum vitamin $E$ concentration for the patients was $12.8 \mu \mathrm{mol} / 1$ (range $4 \cdot 8-50 \cdot 4$ ) (adult normal range $17-47 \mu \mathrm{mol} / \mathrm{l}$ ) but there was no significant difference between the affected group and the other patients (fig 2). Six of the nine affected patients had abnormal liver function tests, compared with 10 of the 34 unaffected patients $\left(\chi^{2}=4.75\right.$, $\mathrm{p}<0.05)$. There was no difference between the two groups in age, sex, Shwachman score, lung function,

Table 2 Serum vitamin $A$ and retinol binding protein concentrations in patients with and without clinical evidence of vitamin $A$ deficiency. Values are expressed as median (range)

\begin{tabular}{llll}
\hline & $\begin{array}{l}\text { Abnormal } \\
\text { dark } \\
\text { adaptation } \\
\text { threshold } \\
\text { or xerosis } \\
(n=9)\end{array}$ & $\begin{array}{l}\text { Normal } \\
\text { dark } \\
\text { adaptation } \\
\text { threshold } \\
\text { no xerosis } \\
(n=34)\end{array}$ & $\begin{array}{l}p \\
\text { Value }\end{array}$ \\
\hline $\begin{array}{l}\text { Vitamin A }(\mu \mathrm{mol} / \mathrm{l}) \\
\text { Retinol binding protein } \\
(\mathrm{mg} / \mathrm{l})\end{array}$ & $0.53(0 \cdot 2-1 \cdot 4)$ & $1 \cdot 1(0 \cdot 5-2 \cdot 3)$ & 0.002 \\
\hline
\end{tabular}

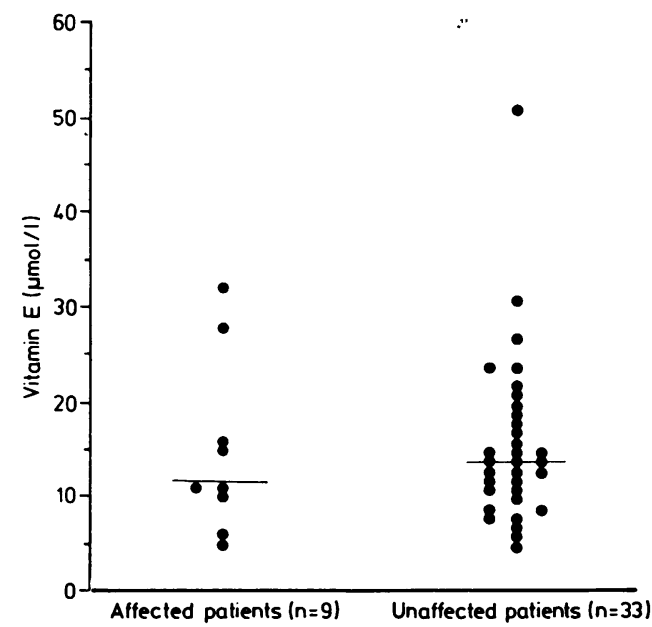

Fig 2 Serum vitamin E concentrations in affected and unaffected patients with cystic fibrosis. Bars indicate median for each group.

Chrispin-Norman score, or percentage of expected weight for height. Three of the affected patients admitted that they had not taken their vitamins regularly in the past.

Mortality in the affected group was significantly increased $\left(\chi^{2}=5 \cdot 65, p<0 \cdot 05\right)$. Four affected patients died within two years of the start of the study (one from liver disease and three from chest disease) whereas two of the 34 unaffected patients died from

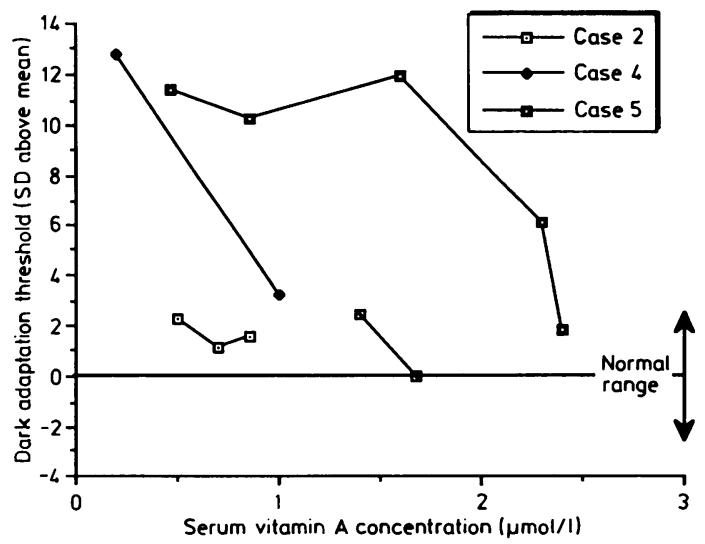

Fig 3 Improvement in the dark adaptation threshold (expressed as the number of standard deviations above the expected mean for age) and the improvement in the serum vitamin A concentration after treatment in four of the affected patients. 
chest disease, one of these also having distal intestinal obstruction syndrome.

Five patients with abnormal dark adaptation thresholds were each treated with a single oral dose of water miscible vitamin A. In all cases, serum vitamin A concentrations rose into the normal range within a few days, but then gradually fell over the next two months in spite of increased daily vitamin supplements. Four patients were well enough to perform repeat dark adaptation tests (fig 3). The response to treatment was variable, as illustrated by the following case reports.

\section{CASE REPORTS}

\section{Case 1}

A 15 year old boy developed jaundice and his lung disease deteriorated rapidly. He had gross conjunctival xerosis and abnormal dark adaptation. His serum vitamin A concentration was $0.2 \mu \mathrm{mol} / \mathrm{l}$ and retinol binding protein $1.0 \mathrm{mg} / \mathrm{l}$. His liver function tests were abnormal: serum alkaline phosphatase 1493 IU/1 (normal range 80-280), alanine aminotransferase $76 \mathrm{IU} / \mathrm{l}$ (normal range 5-40), $\gamma$ glutamyltransferase $215 \mathrm{IU} / \mathrm{l}$ (normal range 10-50), albumin $290 \mathrm{~g} / 1$ (normal range $300-520$ ), bilirubin $61 \mu \mathrm{mol} / \mathrm{l}$ (normal range 5-17). He was treated with an intramuscular injection of 300000 IU oil based vitamin $A$, but after one week his serum vitamin A concentration rose to only $0.3 \mu \mathrm{mol} / \mathrm{l}$ and retinol binding protein fell below $0 \cdot 1 \mathrm{mg} / 1$. There was no improvement in his conjunctival xerosis. He developed liver failure, and died a few weeks later before the dark adaptation test could be repeated. A liver biopsy specimen taken at necropsy showed cirrhosis.

\section{Cases 2 and 3}

Two brothers, aged 8 and 12 years, were found to have conjunctival xerosis. Each had been taking only one multivitamin tablet (2500 IU vitamin A) daily. The younger brother had abnormal dark adaptation, his serum vitamin A concentration was $0.5 \mu \mathrm{mol} / \mathrm{l}$, and retinol binding protein $9 \mathrm{mg} / \mathrm{l}$. His liver enzyme activities were normal apart from alanine aminotransferase of $60 \mathrm{IU} / \mathrm{l}$. He was treated with 25000 IU vitamin A daily in a standard oil based preparation for two weeks. Although his serum vitamin A concentration improved and his dark adaptation threshold returned to normal the conjunctival xerosis persisted for a year. He was treated with 100000 IU water miscible vitamin A orally on two occasions in addition to 8000 IU vitamin A daily. His plasma zinc concentration was $8 \cdot 2 \mu \mathrm{mol} / \mathrm{l}$ (normal range $11-20 \mu \mathrm{mol} / \mathrm{l}$ ) and he was given oral zinc sulphate $220 \mathrm{mg}$ daily for one month, after which the xerosis improved. His older brother also had persistent conjunctival xerosis despite normal vitamin concentrations and normal dark adaptation. His retinol binding protein concentration was $13 \mathrm{mg} / \mathrm{l}$ and liver function tests were normal. His plasma zinc concentration was $9 \cdot 6$ $\mu \mathrm{mol} / \mathrm{l}$. He was given oral zinc sulphate $220 \mathrm{mg}$ in addition to $8000 \mathrm{IU}$ vitamin A daily for one month, after which the xerosis resolved.

\section{Case 4}

A 15 year old girl, who admitted that she had not been taking her vitamin supplements, had grossly abnormal dark adaptation, a serum vitamin A concentration of $0.2 \mu \mathrm{mol} / 1$ and retinol binding protein of $5 \mathrm{mg} / \mathrm{l}$. Her liver function tests were abnormal: alkaline phosphatase $856 \mathrm{IU} / \mathrm{l}$, alanine aminotransferase $90 \mathrm{IU} / \mathrm{l}, \gamma$ glutamyltransferase $161 \mathrm{IU} / \mathrm{l}$, bilirubin $10 \mu \mathrm{mol} / \mathrm{l}$, albumin $340 \mathrm{~g} / \mathrm{l}$. She was treated with 200000 IU water miscible vitamin $A$ and then restarted her usual vitamin supplements. Her night blindness rapidly resolved, and two months later her serum vitamin A concentration was 1.0 $\mu \mathrm{mol} / \mathrm{l}$ and her dark adaptation test almost normal.

\section{Case 5}

A 16 year old girl with severe chest disease and insulin dependent diabetes had grossly abnormal dark adaptation. Her serum vitamin A concentration 9 months previously had been $0.47 \mu \mathrm{mol} / 1$ and retinol binding protein $3 \mathrm{mg} / \mathrm{l}$, although subsequent concentrations were higher. Her liver function tests were normal apart from the serum albumin, which fell to $200 \mathrm{~g} / 1$ despite overnight nasogastric feeding. Her plasma zinc concentration was $15 \mu \mathrm{mol} / /$. She was treated with 200000 IU water miscible vitamin A orally and her daily supplement of vitamin A was increased to $8000 \mathrm{IU}$. Her dark adaptation, however, failed to improve. She was therefore given three further doses of water miscible vitamin $A$ and her daily supplement was increased to 12000 IU. Four weeks later her serum vitamin A level was 2.4 $\mu \mathrm{mol} / \mathrm{l}$. Her dark adaptation threshold returned to normal during the next three months. She died of respiratory failure three months later.

\section{Discussion}

In this study clinical evidence of vitamin A deficiency was found in nine out of 43 patients with cystic fibrosis who had been receiving routine vitamin supplementation and pancreatic enzymes. As the patients had been selected by age, and in some cases were already known to have low serum vitamin A concentrations, this is likely to be an overestimate of the overall incidence of vitamin A deficiency. 
Nevertheless, night blindness and conjunctival xerosis seem to be surprisingly common in adolescent and young adult patients.

We have confirmed that serum vitamin A, vitamin $\mathrm{E}$, and retinol binding protein concentrations are low in patients with cystic fibrosis, and that the dark adaptation threshold rises rapidly below a serum vitamin A concentration of $0.7 \mu \mathrm{mol} / 1$, as described by Fulton et al. ${ }^{10}$ Affected patients are more likely to have low retinol binding protein concentrations and abnormal liver function tests than unaffected patients. The finding of low retinol binding protein concentrations suggests that synthesis and release of retinol binding protein from the liver are deficient. This may explain why some patients responded poorly to treatment with additional vitamin A, because the delivery of vitamin A to the retina is dependent on adequate circulating levels of retinol binding protein. This is illustrated by cases 1 and 5 .

Vitamin E supplementation improves serum vitamin A concentrations, although the reason for this is not known. ${ }^{16}$ All our patients were prescribed vitamin $\mathrm{E}$ supplements, but their serum concentrations were low, suggesting either that the dose prescribed was inadequate or that compliance was poor.

In patients with xerosis or night blindness who fail to respond to additional vitamin A supplements despite achieving normal serum vitamin A concentrations, the possibility of zinc deficiency should be considered. Zinc is required for the release of vitamin $A$ and retinol binding protein from liver stores, and acts as a coenzyme for retinol dehydrogenase in the retina. ${ }^{17}$ In two patients in this study (cases 2 and 3) xerosis resolved with zinc supplementation.

Three of the affected patients had severe lung disease and have since died. It is interesting to speculate what effect vitamin A deficiency may have had on the lung disease. Deficiency is known to cause squamous metaplasia of respiratory epithelia, and may predispose to infection. ${ }^{18}$ It has been suggested that vitamin A supplementation in premature babies may reduce the incidence of bronchopulmonary dysplasia. ${ }^{19}$ Long term studies are required to establish any influence of vitamin $A$ on the progression of lung disease in cystic fibrosis.

We recommend that patients with cystic fibrosis are screened for vitamin A deficiency annually. Serum vitamin $\mathrm{A}$ and retinol binding protein concentrations should be measured and those with serum vitamin A below $1 \mu \mathrm{mol} / \mathrm{l}$ should have a full ophthalmological assessment. Conjunctival impression cytology may better reflect vitamin A deficiency over a period of time than a single serum vitamin A measurement, and we are developing this tech- nique for patients who are unable to perform dark adaptation tests. ${ }^{20}$

Some patients require up to $12000 \mathrm{IU}$ vitamin A and $200 \mathrm{mg}$ vitamin $\mathrm{E}$ daily in order to maintain normal serum concentrations. Not taking vitamin supplements was a factor in at least three patients. The treatment of established vitamin A deficiency with a single oral dose of water miscible vitamin A avoids problems with compliance and seems to be effective in most patients. Provided that serum vitamin A levels are monitored, the development of hypervitaminosis $A$ is unlikely. At present, a water miscible preparation of vitamin $A$ is not available for routine prescription in the United Kingdom.

As more patients with cystic fibrosis are reaching the age of 17 years and learning to drive, the detection and prompt treatment of night blindness has become especially important.

Dr RJ Rayner and Dr JC Tyrrell were supported by the Cystic Fibrosis Research Trust. We thank Dr MB Duggan and Dr J Kelleher for advice, Dr DJ Shale for allowing us to study his patients, and Dr Fothergill (Clinical Research, Roche) for supplying the water miscible vitamin $\mathrm{A}$.

\section{References}

1 Anderson DH. Cystic fibrosis of the pancreas, vitamin A deficiency and bronchiectasis. J Pediatr 1939;15:763-71.

2 Congden PJ, Bruce G, Rothburn MM, et al. Vitamin status in treated patients with cystic fibrosis. Arch Dis Child 1981:56: 708-14.

${ }^{3}$ Underwood BA. The determination of vitamin A and some aspects of its distribution, mobilization and transport in health and disease. World Rev Nutr Diet 1974;19:123-72.

+ Underwood BA. Denning CR. Blood and liver concentrations of vitamins $\mathrm{A}$ and $\mathrm{E}$ in children with cystic fibrosis. Pediatr Res 1972:6:26-31.

5 Rees-Smith F, Underwood BA. Denning CR, Varma A, Goodman DS. Depressed plasma retinol binding protein levels in cystic fibrosis. J Lab Clin Med 1972;80:423-33.

6 Wolf G. Multiple functions of vitamin A. Physiol Rev 1984;64: 873-937.

${ }^{7}$ Petersen RA, Petersen VS, Robb RM. Vitamin A deficiency with xerophthalmia and night blindness in cystic fibrosis. $\mathrm{Am} \mathrm{J}$ Dis Child 1968;116:662.

8 Abernathy RS. Bulging fontanelle as presenting sign in cystic fibrosis. Vitamin A metabolism and effect on CSF pressure. $\mathbf{A m}$ $J$ Dis Child 1976:130:1360-2.

9 O'Donnell M. Talbot JF. Vitamin A deficiency in treated cystic fibrosis: case report. $\mathrm{Br}$ J Ophthalmol 1987:71:787-90.

10 Fulton AB, Hansen RM, Underwood BA, Shwachman H, Barg DC. Scotopic thresholds and plasma retinol in cystic fibrosis. Invest Ophthalmol Vis Sci 1982:23:364-70.

"Neugebauer MAZ, Vernon SA, Brimlow G, Tyrrell JC, Hiller EJ, Marenah C. Nyctalopia and conjunctival xerosis indicating vitamin A deficiency in cystic fibrosis. Eye 1989 (in press).

12 Chase HP. Long MA. Lavin MH. Cystic fibrosis and malnutrition. J Pediatr 1979;95:337-47.

13 Stewart-Truswell A. Malnutrition in the Third World-II. Br Med J 1985:291:587-8.

${ }^{14}$ Shwachman H, Kulczycki LL. Longterm study of 105 patients with cystic fibrosis. Am J Dis Child 1958:96:6-15.

15 Vernon SA. Neugebauer MAZ, Brimlow G. Tyrrell JC, Hiller 
1156 Rayner, Tyrrell, Hiller, Marenah, Neugebauer, Vernon, and Brimlow

EJ. Conjunctival xerosis in cystic fibrosis. $J R$ Soc Med 1989;82:46-7.

${ }^{16}$ Ekvall S, Mitchell A. The effect of supplemental vitamin E on vitamin A serum levels in cystic fibrosis. Int $J$ Vitam Nutr Res 1978;48:325-32.

17 Solomons NW, Russell RM. The interaction of vitamin A and zinc: implications for human nutrition. Am J Clin Nutr 1980;33: 2031-40.

18 Chandra RK. Increased bacterial binding to respiratory epithelial cells in vitamin A deficiency. Br Med J 1988;297:834-5.
${ }^{19}$ Shenai JP, Kennedy KA. Chytil F, Stahlman MT. Clinical trial of vitamin A supplementation in infants susceptible to bronchopulmonary dysplasia. J Pediatr 1987;111:269-77.

${ }^{20}$ Tseng SCS. Staging of conjunctival squamous metaplasia by impression cytology. Ophthalmology 1985;92:728-33.

Correspondence to Dr EJ Hiller, City Hospital, Hucknall Road, Nottingham NG5 1PB.

Accepted 30 March 1989 